\title{
Carlos V y el primer cerco de Viena en la literatura hispánica del xv
}

\author{
Xavier Sellés Ferrando \\ Agregado Cultural de la Embajada española en Viena
}

Entre todas las efemérides que tuvieron lugar en el siglo xv sobre el suelo austriaco, no hubo otra más famosa en toda Europa como la del primer cerco de Viena por los turcos en el año 1529. Se vió en la derrota sufrida por el sultán Solimán la liberación definitiva de Europa de una situación de angustia causada por los continuos acosos del ejército otomano y no se pensó que poquísimos años después se pondrían otra vez en camino de Viena con un ejército todavía mayor.

A cuarenta años de la expulsión de los árabes de España, la victoria de la cristiandad sobre los mahometanos era recordada con entusiasmo tambien más allá de los Pirineos. No es de extrañar, por tanto, que el rechazo de los turcos obtuviera a su vez una resonancia en la literatura hispánica del siglo xvI.

Recordemos, sin embargo, los antecedentes históricos. En marzo de 1430 Venecia no pudo defender más los Dardanelos de los ataques turcos y por esta causa cayó Tesalónica, la penúltima ciudad griega, ante los otomanos. La cristiandad se sobrepuso todavía para organizar una contraofensiva, pero la batalla de Varna en 1444 significó una nueva derrota para Occidente, y para los vencedores otomanos significó la base de su poderío en Europa. Muy grave fue que se perdiera también sin poderla salvar la ciudad de Constantino, pues el 30 de mayo de 1453 entraba en la megápolis del Bósforo el sultán Mohamed II. Le dio el nombre de Estambul (Sede del Dominador) convirtiendo la catedral Hagia Sofía en mezquita, construyéndose con el tiempo otras 132, además de 26 bibliotecas, 17 hospitales, 33 palacios y 7 acueductos. Con Solimán era ya en 1520 capital del califato y el Imperio Otomano alcanzaba su máxima extensión. También su harén, pues contaba con 400 dependencias, y su cocina con 491 cocineros. Todo ello da también indirectamente idea de su poderío.

En 1522 los Caballeros de la Orden de Malta, que habían ofrecido tan grande resistencia por mar a los corsarios turcos, tuvieron que abandonar la fortificación de Rodas. 


\section{Xavier Sellés Ferrando}

Ya durante el primer año del gobierno de Solimán, cayó Belgrado el 29 de agosto de 1521 en sus manos. Además de aumentar su poderío militar ganó también diplomáticamente una buena ayuda: Francia sabía que los otomanos al pretender Hungría pretendian conquistar también las tierras centroeuropeas del Sacro Imperio.

El 27 de junio de 1526 cayó Petrovaradin (Peterwardein), la fortificación junto al río Drave, en manos turcas. El 29 de agosto, en los piélagos del Danubio junto a Mohacs caía el ejército húngaro en pleno, en sólo hora y media, aniquilado por los otomanos: cayeron magnates magiares, cayeron los obispos que fueron a luchar y cayó el Rey que contaba sólo veinte años. Se empezó a temer lo peor para Austria y sobre todo para Viena. El sultán no recogió la corona húngara que estaba libre, como si levantarla y quedársela no fuera digno de su persona. Se aseguró, sin embargo, la obediencia de $\$ 30$ reinos» y se autoproclamó kemperador de emperadores, príncipe de príncipes y sombra de Dios sobre ambos mundos».

Parecía como si los otomanos arrasaran a un Occidente débil como once siglos antes lo hicieran los germanos con los romanos.

En el transcurso del año 1526 se había elegido en Hungría a dos reyes por no poder ponerse de acuerdo: según el Derecho dinástico y según los tratados, se constituyó rey el archiduque Fernando de Habsburgo ante una minoría, y según el Derecho electoral del pueblo húngaro fue elegido rey por la mayoría de la nobleza magiar el voyvoda de Transilvania (Siebenbürgen) Juan Szapolay, que fue llamado «conde von Zips» por los austríacos. Éste reconoció la soberania de Solimán en Hungría y no solamente puso tropas a su disposición, sino que tomó parte personalmente en el ataque a Viena. Por si no fuera poco, muy pronto se planteó el problema de cómo pagar los sueldos al ejército defensor del recién nombrado monarca Fernando de Habsburgo que claramente no disponia de medios para ello. El emperador Carlos $\mathrm{V}$ disponía, gracias a las posesiones españolas en América, de respetables cantidades de metales preciosos que permitirían más tarde ayudar a su hermano. Sin embargo, hay que considerar los conflictos que de repente se le plantearon a éste.

Fernando había implorado en vano ayuda contra los turcos a su hermano, que en su día le había nombrado Señor de Austria. El Emperador, que estaba en guerra con el Papado, con Francia y con la República de Venecia, no pudo prescindir de sus ejércitos ni tampoco mandar inmediatamente una ayuda económica. Todo lo contrario: el 24 de julio le pidió a su hermano que destinara, tanto un contingente de caballería como de infantería, a Italia, para apoyarle. Solamente la Gobernadora de los Paises Bajos, María de Hungría, destinó a 1.500 españoles de los famosos Tercios de Flandes a ayudar a su hermano. Serán los españoles los que, bajo el mando de Luis de Avalos, tomarán parte, más tarde, en la defensa de Viena. A principio de 1529 navegaban Rin arriba, pero antes de ir a Viena tomaron parte en una acción bélica en Carniola (Krain), cerca de Venecia y allí, por faltarles la paga, se amotinaron y, por esta causa, de los $\mathbf{1 . 5 0 0}$ hombres sólo llegaron a Viena en septiembre la mitad. 
El Emperador, con sus múltiples intereses y trabajos, estaba siempre imposibilitado y ocupado en algún lugar de Europa, permaneciendo fuera de la zona oriental, asimismo gravemente amenazada. Por esta razón aconsejó a su hermano llegar a un acuerdo amistoso con Szapolay. En Alemania había mucha gente, tanto entre la nobleza como entre el pueblo, que deseaba «a ese Fernando, el español, que estaba tentando a Dios, cayera en manos de los turcos», pues veían que no ayudaba al Emperador ${ }^{1}$.

Desde hacía siglos no se había dado una amenaza tan grave, tanto a la cultura como a la religión existentes en Occidente. Hasta el propio Martín Lutero levantó su voz para advertir del peligro en que se encontraba el Emperador que era el defensor de los derechos y de la fe de la Cristiandad, diciendo que se le debía prestar apoyo, y acusando a Venecia de «Verräterei», es decir, no sólo de traición sino de traición continua.

Con el papa Clemente VII se logró, el 29 de junio en Barcelona, un acuerdo, y con Francia se firmó el 5 de agosto la Paz de Cambrais, llamada de Las Damas. Sin embargo, era demasiado tarde para poder destinar las tropas imperiales estacionadas en Italia a defender Viena del ataque turco. El angustioso manifiesto que dirigió Fernando el 28 de agosto a toda la Cristiandad quedó sin respuesta: no obtuvo ni dinero ni tropas. Solamente un puñado de españoles que en su mayoría murieron.

Un mes después llegó el momento temido: el primer cerco de Viena había empezado. Es interesante indagar el papel que jugaron los españoles: según el Diario que redactaban los sitiados ${ }^{2}$, el 25 de septiembre de 1529 menciona que la gente que normalmente habitaba en pueblos vecinos de la Baja Austria fue destinada a defender la capital en la «Judenturm» (torre de los judíos) y los españoles en el lugar llamado «Elend», donde construyeron una fortificación poniendo también algunos cañones. El día 27 se dice que se organizaron ocho «Fähnlein» con soldados rasos y «ain fendlein Hispanier puxenschützen» otro más con españoles (un Fähnlein constaba de $\mathbf{4 2 0}$ hombres con armas de fuego) para defender la Roten Turm (torre roja) y alejar al enemigo de los puentes.

El día 29 de septiembre tuvo lugar una escaramuza que fue célebre. Soldados de los tercios españoles y otros de infantería sorprendieron a un grupo de turcos que habían dejado sus armas amontonadas, comiendo uvas en una viña junto a la Schottentor. «Auffs mindest drei fendlein» (más de 1.200 turcos) fueron perseguidos hasta el Danubio, muriendo todos en el ataque o por no saber nadar. En esta época surgen muchos de los refranes y expresiones todavia usados hoy en día: «ir a por uvas» podría haber nacido en este episodio - según opinó el catedrático de Salamanca don Feliciano Pérez Varas- pues, como es sabido, significa querer hacer algo agradable, encontrándose de repente con graves peligros.

\footnotetext{
${ }^{1}$ TurTschek, C., Die Türkempolitik Ferdinands I. von 1529-1532, Dissertation, Wien, 1968.

${ }^{2}$ PrandL, H., Berichterstattung über die 1. Wiener Türkenbelagerung 1529, Dissertation. Wien, 1957
} 


\section{Xavier Sellés Ferrando}

El 6 de octubre dice el Diario que la fuerza ofensiva de los defensores estaba muy mermada puesto que hasta los españoles, que estaban muy hechos a la guerra, sufrieron graves pérdidas y tuvieron que retirarse de varios puntos. El primer asalto turco, después de dura lucha, pudo ser repelido. Menciona que «los españoles tuvieron una buena cosecha» tumbando a mucho enemigo «denn es war jederman lustig und girig» (era para cada uno causa de diversión y avidez) luchar contra los turcos.

Más adelante cuenta como entre las tres y las cuatro de la tarde del 10 de octubre, cuarenta soldados junto con bastantes españoles, («bei XI Knecht mit etlichen Hispaniern») atacaron a los turcos llevándose a cinco camellos y mucha pólvora fina. Se supone que las raciones de carne de camello fueron rápidamente repartidas entre los hambrientos defensores.

Sin embargo, un día después, se cayó el techo de la Kärntner Turm matando a muchos soldados, entre ellos a bastantes españoles. Otros soldados cayeron en el foso de la muralla y bastantes españoles sobre el tejado de una casa adosada al muro: varios de ellos pudieron volver pasando a través de un boquete abierto en la muralla por la artillería turca, pero uno de ellos no pudo salvar su vida, pues se dedicó a echar piedras contra turcos para distraerlos mientras sus compañeros se salvaban, hasta que fue abatido por las balas.

Repetidas veces se menciona como los soldados españoles «mit aufgerecktem fenlin und werhafter Hand, ritterlich und künlich» (con la bandera en alto y el arma en la mano, caballerosa y atrevidamente) se lanzaban al ataque hasta que el 15 de octubre los otomanos empezaron a preparar su retirada.

En el primer sitio de Viena, se calcula murieron más de 1.500 personas, o sea, aproximadamente una décima parte de los sitiados. Sólo sobrevivieron unos 250 españoles, pues también se calcula que más de 500 murieron heróicamente. Los temidos jenizaros turcos, tropas de asalto, murieron en muchísimo mayor número.

Entre las tropas del rey Fernando figuran «Loys de Avalos (Maister de Campo), Jan de Salinas, Melchior de Villarial, Jan de Aguillera und über ungeferlich 700 Hispanisch Knecht». Añade que los alféreces Jörg Manrique, Christof de Aranda, Loys de Calathayut, Alonso de Eredia, Zapada, Valderama y Vallorens salieron con vida, así como Khirosz (Quirós), Navares y Cordanes, pero Camargo murió («aber Camargo ist umkhumben»). Se sabe también que sobrevivió un soldado llamado Juan Ciudad, con vida de aventurero, hasta que diez años después en Granada, bajo el lema $\ll E l$ corazón manda», fundó el primer hospital y empezó a realizar una labor pionera en la atención a los enfermos, pasando a ser llamado Juan de Dios y más tarde a ser canonizado.

La versión otomana de Istvabfy, sobre el primer asedio de Viena por los turcos, se refiere a la crónica de Ibrahim Pecevi y menciona repetidas veces las acciones bélicas de los españoles. Especialmente dedica unos comentarios a la intervención de un centenar de españoles que atacaron y mataron a un numeroso grupo de turcos que estaba 
ocupado en una viña cercana a la muralla. Estaban preparando unos atijos con las raíces de las cepas, que podían llegar a tener hasta cuatro metros de longitud, para ser colocados sobre las fosas, de forma que taparan las minas alli escondidas que, al explotar, harían saltar parte de la muralla. La realidad es que los turcos no estaban comiendo tranquilamente uvas, habiendo amontonado sus armas en un descanso... La versión española era extremadamente chistosa y la turca demostraba, a su vez, la extremada peligrosidad de sus propósitos.

También se menciona que en un contrataque en el que participaban españoles entre los 800 soldados que lo llevaban a cabo, uno de ellos dio un grito de mando que fue malentendido y dio ocasión a los sitiadores a realizar una matanza en la que pereció uno de los oficiales españoles y muchos de sus soldados. Señala que a pesar de la debacle los sitiados pudieron encontrar varias minas que fueron apartadas también por varios españoles antes de que los turcos las pudieran activar. Poco después hicieron explotar todas las que habían puesto junto la muralla o las torres, causando graves desperfectos.

El cronista turco reflejó muy objetivamente los sucesos diariamente acaecidos, por lo que la versión de Ibrahim Pacevi es muy apreciada por los historiadores. Al final hace constar exactamente que el nombre del oficial español caído era García Guzmán.

No puede dejarse de mencionar tampoco las notas escritas durante el asedio de Viena que fueron descubiertas por un sacerdote húngaro durante su estancia en Roma, el año 1698, en el departamento de manuscritos de la Biblioteca Vaticana, bajo el título Expugnatio urbis Viennae in Austria, facta per turcarum regem, 21 septembris anni 1529. En estas breves notas se hace constar también la participación y muerte de varios centenares de soldados españoles.

El Sultán y el Gran Visir condujeron su ejército a marchas forzadas hacia Estambul, donde llegaron el 16 de diciembre. Para ellos estaba claro que la expedición «contra los polvorientos infieles» no estuvo favorecida por Alah. Sin embargo, Solimán presumía de haber alcanzado algo importante: «He conquistado el reino de Hungria -escribió a Venecia - y entregado su corona a Zapolya», y eso era verdad. La derrota que tuvo que encajar en Viena, como Gran Señor que era, la camufló como si hubiera sido una escaramuza fronteriza. Estaba claro que esperaría la próxima oportunidad para realizarla con éxito. Su propósito era, además de Hungria, ocupar Austria, Alemania y todo Centroeuropa.

Sus ojos ya no se apartaron, pues, de las tierras danubianas que habían pisado sus pies. Por esta razón, la historia del sitio de Viena en 1529 estaría sólo contada a medias, si no mencionáramos lo que ocurrió poquísimos años después. Se dijo que cuando Solimán volviera no lo haría sólo para sojuzgar a «los miserables habitantes de Viena», sino para disputar personalmente la soberanía del mundo al propio Emperador. Recordamos inmediatamente a Federico Barbarroja y al sultán Saladino cuando oimos hablar, en la literatura hispánica, de un duelo de hombre a hombre entre el 
sultán Solimán y el propio emperador Carlos V, para enfrentarse en un autoproclamado juicio de Dios. El desafiado no tenía porqué evitar tal juicio. Al menos esta idea fue recogida por el propio Lope de Vega, como veremos más tarde.

El miedo al peligro turco se implantó tanto en la conciencia de princípes alemanes como en la del pueblo de las tierras del imperio, y aunque no estaban en situación de colaborar inmediatamente, querían aprobar se organizara un fuerte contingente de defensa, en la Dieta de Augsburgo. Por su parte el Papa había excomulgado a Szapolay, y el emperador Carlos V, como vimos, había logrado favorables tratados de paz con sus poderosos enemigos, tanto en Barcelona como en Cambrai y Bolonia. Por otro lado, ni el Emperador ni su hermano Fernando habían pensado complacer en lo más mínimo los deseos del Sultán de renunciar al Reino de Hungría en favor del «Conde von Zips».

Fernando hubiera reconquistado con gusto la parte norte y montañosa de Hungría, pues era una condición importante para seguir obteniendo nuevos créditos de los banqueros Fugger a fines de 1529. Tampoco pudo lograr un tratado de paz que aclarara la situación en el Este. Sabemos, por el contrario, las grandes concesiones que tuvo que hacer en 1530 al visir Ibrahim Pacha cara las exigencias del Sultán. Estaba dispuesto a pagar tributo, aunque lo llamó subvención, por la parte Norte y Occidental de Hungría (hoy Croacia) y hasta a cederlas a Zapolya si se fijaba en un Tratado que Fernando heredaria toda Hungría a su muerte, pues se esperaba que no tuviera descendencia ${ }^{3}$. Como los magnates húngaros, sin tener en cuenta a Fernando ni a Zapolya, se sentian seguros bajo el dominio turco, el emperador Carlos $\mathrm{V}$ planteó a su hermano la posibilidad de que hubiera una nueva invasión turca. Le quitó además la esperanza de que entrara en funciones el contingente planeado por los príncipes de la Cristiandad. Es más, le señaló el peligro de ser impedido por ellos en su actuación porque conocían las dificultades económicas que atravesaban tanto Carlos V como Fernando. Entretanto el peligro de una nueva invasión turca fue siendo cada vez más real. A fines de 1531 se sabía que los turcos se armaban tanto por mar como por tierra y efectivamente en abril de 1532 el Sultán abandonaba Estambul en una expedición que avanzaba siguiendo el Danubio. Mientras que el Sultán especulaba en la división producida por las querellas de fondo religioso que existían en la Cristiandad, a fines del veráno de 1532 , Occidente había podido reunir un ejército de 100.000 hombres que esperaban a los turcos en pie de guerra junto al Danubio frente a Viena.

Para los coetáneos como para las generaciones posteriores era incomprensible que la expedición bélica del Sultán, mayor que la realizada tres años antes con el asedio (se calcula estaba compuesta por más de 250.000 hombres), terminara sin más y tan repentinamente. El factor miedo ante las jugadas de la metereología que pronosticaba seguirian las grandes lluvias, vientos y nieves, que harían imposible mover la artillería pesada, junto con el complejo psicológico de estar ante un gran número de buenos

\footnotetext{
${ }^{3}$ Mitteilungen des Veneins für Gescbichte der Stadt Wien, Band IX/X (1930).
} 
soldados - aunque era sólo la mitad de grande- capitaneados por el propio Carlos V, que tenía fama de muy buen guerrero y disponía de una artillería mejor y más ligera que la turca, motivaron su retirada sin llegar a una batalla decisiva. Ya en las tres últimas semanas de agosto el enorme ejército se estancó en la frontera austríaca ante la resistencia ofrecida por la fortaleza de Güns/Köszeg (hoy en Hungría), gracias a Niklas Jurischitsch, ante el asombro de todos. A principios del mes siguiente salieron unos 16.000 jinetes turcos en dirección a Viena, devastando la Estiria y la Baja Austria, pero fueron aniquilados por las tropas imperiales a fines de septiembre.

Existen cantidad de cancioneros en los que se deplora y se advierte del peligro turco y se exulta a las tropas defensoras y al Emperador, por haber rechazado al invasor. Canciones y antiguas «profecías» proceden todas del período 1529-1532, extendiéndose por todo Centroeuropa: no había para menos. La importancia de la resistencia ofrecida hasta el límite de lo posible en otoño de 1529 cobró tres años después toda su importancia, pues de alguna manera acomplejó al potente ejército turco, que después del segundo intento fallido ya no insistió más hasta siglo y medio después, es decir, hasta 1683.

Contemplemos todavía lo sucedido en 1532 y planteémonos algunas preguntas como: ¿dónde estaba el Emperador?, chubo también esta vez tropas españolas? ¿Por qué en Austria, tanto ahora como antes, nadie habla de lo que pudo haber pasado?

Carlos V llega a principios del 1532 a Alemania ${ }^{4}$. Su propósito es convocar un «Reichstag», para asegurar desde la Dieta la paz, hasta que un concilio (Trento 1545-1563) resuelva el conflicto religioso. Tiene esperanzas de poder regresar pronto a España y de empezar a organizar la conquista de Túnez.

A mitad de enero de 1532 decide irse de Bruselas pero de repente la situación se complica de tal manera que retrasa su viaje. Varios sucesos, no sólo lo que se teme pase en Viena, ponen en peligro la paz. En los propios Países Bajos, que gobierna con gran acierto su hermana María, no hay tranquilidad. Por una parte, hay grandes inundaciones que causan graves daños materiales y personales. Por otra, la recaudación de nuevos impuestos para financiar las tropas que han de defender la Cristiandad de la invasión de Solimán en Viena provocan una revuelta en Bruselas. Carlos aconseja a su hermana que se traslade a Brujas o Gante. Desde Regensburg escribe a la Emperatriz anunciándole que conducirá personalmente el ejército que se enfrente al turco, reuniendo todos los medios que estén a su alcance. Añade: «confío totalmente en Dios, pues es su causa y por ello me favorecerá y ayudará a que la santa fe no sea aplastada por los mahometanos y pueda seguir siendo exaltada y expandidax s. Solamente para alcanzar este fin ha cedido ante los protestantes alemanes y obtenido gran ayuda como era un ejército de 29.000 infantes y 5.000 caballos. Su hermano Fernando piensa obtener el apoyo por el lado austríaco y bohemo de $\mathbf{3 0 . 0 0 0}$ soldados y de la caballería ligera

4 Carlos V a la Emperatriz, Regensburg, 6 de abril 1532.

' Carlos V al arzobispo de Toledo, Bruselas, 17 de enero 1532. 
magiar. El propio Carlos $\mathrm{V}$ piensa obtener hombres y dinero de los Países Bajos y de Italia, España y Polonia, contando con 30.000 infantes y 20.000 caballos.

Los informes confidenciales del embajador imperial Lope Hurtado ante la Corte portuguesa delatan que en el verano de $1532^{6}$ existe una enorme actividad diplomática entre Venecia, Francia y Lisboa, contraria a los intereses del Emperador. Los turcos han anunciado que decidirán quién recibirá los transportes de especias provenientes de Asia. La duda está si será para Venecia o para Portugal en el caso de que el rey Juan III renuncie a prestar ayuda a las tropas imperiales que han de defender Viena. Tanto el rey de Francia como el de Inglaterra quieren que Portugal decida no apoyar, pero el Rey, molesto por tantas presiones, decide donar los 100.000 ducados prometidos a Carlos V.

Entretanto se concentran en Regensburg las tropas reclutadas en Alemania a las que se les unen las que envía María desde los Países Bajos y las procedentes de Italia. El duque de Alba atraviesa Francia a marchas forzadas y enferma, siendo cuidado por su compañero y amigo Garcilaso de la Vega. Más tarde, «con amorosos ojos adelante, Carlos, César triunfante, lo abraza cuando desembarca de Ratisbona», canta la Égloga del poeta. Viena y sus alrededores se preparan para la defensa, concentrándose en la capital gran cantidad de armas y alimentos.

Las lluvias torrenciales que empantanaban la llanura húngara y la resistencia de Güns/Köszeg, sólo a unos 120 kilómetros de Viena, posibilita a Carlos V llegar a tiempo, ordenando sus tropas ya en Linz, después de utilizar su desplazamiento fluvial ${ }^{7}$. Le acompañan ya experimentados estrategas al mando de Federico II del Palatinado, como el conde de Nassau, Antonio de Leyva, y el marqués del Vasto, así como el joven duque de Alba. El propio Emperador anuncia a su hermana María a mitad de agosto: «espero que mis españoles (utiliza el posesivo) lleguen esta semana a Innsbruck». Por su parte la Emperatriz le comunica el 21 de julio: «Hace ocho días que el duque de Béjar salió para servir al Emperador en la campaña contra el turco y como otros miembros de la nobleza han sido animados a hacer otro tanto, la idea del duque a venido muy a propósito...»

Naturalmente debían reunir también el dinero necesario. La revuelta de Bruselas refleja ya el esfuerzo que tenían que realizar los Países Bajos. La Dieta puso a dispósición las tropas en Alemania, pero Castilla debía colaborar económicamente. En primer lugar el Emperador contaba con 500.000 ducados procedentes del rescate de los príncipes franceses que había aprisionado, pero añadió los préstamos que le hizo la nobleza: el duque de Medina Sidonia le dio 50.000 ducados y la duquesa de Béjar la inmensa cantidad de 60 millones de maravedís, es decir, unos 160.000 ducados. Las Cortes aprobaron el préstamo de 180 millones de maravedís a devolver en dos años, no sin haber hecho un gran esfuerzo, «pues el pueblo, que es el que los pagará, está cansado

\footnotetext{
- Archivo General de Simancas, E., leg. 369.

7 Garcinaso, Segunda Égloga, verso 1501/1503 del romance comentado.
} 
y pobre por las miserables cosechas de los últimos años...». Todo lo recaudado bastaba para hacer frente al enorme peligro. El propio Emperador llegó a Viena el 23 de septiembre. Como sabemos no tuvo lugar la gran batalla ni menos otro cerco. Sin embargo, con todo derecho se puede afirmar que Carlos $\mathrm{V}$ ganó la partida al turco de la manera más limpia. El Emperador, sin embargo, parafraseó el conocido «veni, vidi, vici» de Julio César, diciendo «vine, vi y Dios venció». A partir de aquel momento el Emperador piensa que puede marcharse dejando confiadamente el mando a su hermano Fernando. Éste, por su parte, pensó no ser oportuno exponerse seguidamente a reconquistar Hungría.

Carlos V había permanecido once días en la orilla izquierda del Danubio frente a Viena, pero como había en la propia Viena una epidemia de peste, abandonó la Baja Austria. El 4 de octubre está todavía en Viena pero el 11 ya había llegado a Leoben ${ }^{8}$. Fue ésta la única vez en su vida que estuvo en esas tierras ${ }^{9}$. El deseado regreso a España podía ahora tener lugar pasando por Italia para encontrarse de nuevo con el papa Clemente VII en Bolonia. Durante esta estancia, en enero de 1533, Ticiano pinta el famoso primer retrato de cuerpo entero del Emperador con un gran perro dogo al lado, que está en el Museo del Prado.

En el decenio que va de 1522 a 1532, Viena se jugó su futuro histórico, pasando a ser considerada no sólo el baluarte de la Cristiandad contra el Islam, sino del catolicismo frente a las confesiones religiosas reformadas por los alemanes. Esta situación no le facilitó sino que le dificultó su destino. El espléndido mapa turco que muestra el cerco de Viena, pinta la ciudad rodeada de unos trazos azules, como si fuera una isla en un océano. Para los turcos Viena era la «ciudad de la manzana de oro», la más apetitosa, la otra parte de sí mismos, la ciudad por excelencia que podía ser la capital de un imperio universalista «cristiano-musulmán» que abarcaría de las estepas centro-asiáticas hasta las frondosidades centroeuropeas. Es curioso que ambos imperios se hundieran juntos en 1919 después de aliarse por primera vez.

En aquellos años, sin embargo, Viena se tomó muy en serio su papel de ciudad fronteriza, pues nadie creía que si el turco la hubiera conquistado hubiera sido posible o fácil echarle. Así había pasado con Budapest: los húngaros trasladaron por dos siglos su capital a Bratislava. Los emperadores de la Casa de Austria reforzaron intensamente sus bastiones y torres, gozando al pensar que estando débilmente fortificada, Viena había demostrado ya ser inexpugnable, quedando así hasta la gran reforma urbana del siglo XIX. Los soldados de los Tercios de Flandes que la habian defendido entonces al grito de «Santiago» y «España», cambiando su función de «Matamoros» por la de «Mataturcos», influyeron en que todo Austria se llenara de ciudades, pueblos, iglesias, capillas, pasos, cerros, montes, etc. con el nombre del Patrón de España, esperando

${ }^{8}$ Carlos V a María, Leoben. 11 de octubre 1532.

- FonseCA Y AGunLerA, M. de, Estancias y viajes del emperador Carlos $V$ desde su nacimiento basta su muerte. 
que también les librara del peligroso y cercano invasor musulmán. Por todo ello es casi lógico que los literatos hispánicos dieran rienda suelta a su fantasía sin prestar gran atención a las fechas, como hubiera hecho un historiador, al tratar estos hechos.

Es interesante mencionar el estudio que Hayden White publicó en 1986 bajo el título Las ficciones en la representación de lo fáctico en el que señala algunas diferencias entre el discurso que hace un historiador y el que hace un autor de literatura de ficción histórica:

Los historiadores - dice- tienen que ver con sucesos que se pueden encuadrar en un lugar y tiempo determinados. Son sucesos que, en principio, se han tenido en cuenta porque han podido ser observados. Los autores literarios de ficción histórica - poetas, novelistas y dramaturgos - utilizan tanto el método de los primeramente descritos como el de representarse algo nuevo e hipotético, inventándose nuevos sucesos ${ }^{10}$.

A ello responde Roger Chartier diciendo ser cierto que la redacción histórica es siempre una narración que usa las mismas formas que la redacción de hechos imaginarios pero prescinde de lo que se podría llamar fiction-making operation:

Contra tal programa hay que tener en cuenta que para la redacción histórica el reconocer un hecho es algo constitutivo. Fundamenta las operaciones especificas de la historia: encontrar y calibrar los datos obtenidos, formular hipótesis, verificar y criticar los resultados, asi como tratar sobre la adecuación del discurso reconoscible con el discurso fáctico. Aunque el historiador escriba en forma literaria no produce literatura y esto por un doble motivo: por su dependencia de los archivos, y, por tanto, del pasado reflejado en los archivos, y también por su dependencia de los criterios científicos y de los procedimientos de su oficio de historiador ${ }^{11}$.

Éste no es lugar adecuado para entrar en este complejo problema de forma exhaustiva y baste repetir una afirmación, aunque parezca sumamente banal: que tampoco los textos literarios y los de ficción histórica son lo mismo, pues nada más fácil para ésta que subir de esta forma el escalón necesario para ser literatura y tener su categoría. Los que siempre han sido contrarios a la lírica han dicho que en ella todo es hueco y lleno de mentiras artísticamente presentadas. Puede ser que nada tenga que ver con la realidad, pero sin duda todo puede ser de una gran calidad literaria.

Sin embargo, reconocemos al comparar los dos textos citados que el de White tiende a una relativización posmoderna de la investigación histórica como ciencia, al señalar la importancia de la imaginación literaria; por otra parte Chartier, como representante de la joven generación francesa de la nouvelle bistoire, recuerda que a pesar de que

10 WHITE, 1986, p. 145.

11 Chartier, R, Zeit der Zweifel. Zum Verständnis gegemuärtiger Geschichtsschreibung, en CONRAD y KESSEL (eds.), 1994, pp. 83-97. 
las formas redaccionales pueden mostrar cierta ficcionalidad, la historia no puede abandonar ni olvidar su pretensión de ser una ciencia que opera con datos controlables.

Tanto el romance anónimo o las Églogas de Garcilaso que aquí se citan, como «la comedia famosa» de Lope o el drama de Rojas Zorrilla - aquí tratados - no han dado nunca pie a una investigación histórica sobre los temas surgidos alrededor del primer cerco de Viena, pero sí que han sido dignos - aparte de su indudable valor literariode ser tenidos en cuenta, dentro del contexto de dichos hechos históricos. No es ninguna desgracia, pues, que algunos textos historiográficos sean tratados como víctimas al ser sacrificados en el altar de la literatura. Si el literato es de categoría y su obra es portadora de los valores culturales de su tiempo, la creación será admirada a lo largo de la historia, también por los historiadores.

Dentro de los muchos tesoros de la literatura española hay dos romances que se refieren al primer sitio de Viena. El primero es de Gabriel Lobo Laso, llamado Garcilaso de la Vega. Fue testigo en 1531 de la boda secreta de su sobrino con Isabel de la Cueva, heredera del duque de Albuquerque, a pesar de la prohibición imperial establecida en una real cédula. El enfado de Carlos $\mathrm{V}$ era natural, así como la orden de aprehensión de Garcilaso. Como el poeta acompañaba al duque de Alba a Regensburg, el castigo de un corto confinamiento fue retrasado hasta el verano de 1532, teniendo lugar en una isla del Danubio, pasando luego el poeta a Italia, por lo que no fue testigo presencial de los grandes preparativos de defensa contra los turcos.

Ensalzó el papel desempeñado por el duque de Alba, al estrenarse en las armas, pues sólo contaba veinticuatro años el que se haría infelizmente famoso como Gobernador de los Paises Bajos; por algo era su amigo y protector. Describió a sus personajes y hechos, como en el principio de su obra al pasar los Pirineos, con plena libertad poética. Garcilaso fue un gran lírico renacentista pero no un cronista. Sus famosos versos honran su elegante pluma:

Danubio, rio divino, que por fieras naciones vas con tus claras ondas descurriendo...

En el verso 1675 de su segunda Égloga, menciona la amenaza del turco ya superada:

Resplandeciente y clara, de su gloria
pintada, la Victoria se mostraba;
a César abrazada y no parando,
los brazos a Fernando echaba al cuello.
El mostraba d'aquella sentimiento
por ser el vencimiento tan holgado.

Garcilaso constata de alguna forma que a Fernando no le entusiasmó haber obtenido un victoria tan fácil, pues como sabemos los otomanos al llegar a unos 100 kilómetros 
de Viena se retiraron sin presentarse en un campo de batalla. Podía hablarse de victoria en 1529 pero no en 1532, afirmaron algunos en Centroeuropa, pero el hecho de que el Emperador hubiera considerado muy necesaria su presencia esta segunda vez en Viena señaló su gran intuición bélica y política, pues con este esfuerzo y unas oportunas inundaciones bastó para alejar al poderoso enemigo y darle una victoria sin apenas ser necesario verter sangre.

$\mathrm{El}$ autor del segundo romance es desconocido. Se conoce su existencia al editarse la Rosa Real de Juan de Timoneda el 1573 en Valencia. Se escribió naturalmente antes de la fecha señalada. Allí se pueden leer los siguientes versos:

\author{
En el templo estaba el turco, \\ el turco en el templo estaba; \\ Haziendo la zalá está, \\ y a Mahoma suplicaba, \\ que le quiera dar victoria \\ contra Carlos, rey de España; \\ Que si esta vez le venciera \\ la cristiandad es ganada.
}

Al final de este romance anónimo hay, como curiosidad cultural e histórico-literaria, una lista de todos los Grandes de España que tomaron parte en la defensa de Viena. En el ataque participa Luis de la Cueva, hermano de Isabel, duquesa de Albuquerque, que causa veintidós heridas a un tal Baltasar de Transilvania, único superviviente de los 16.000 jinetes que constituían la avanzadilla turca del ejército que iba a asediar Viena, añadiendo que el Sultán decidió huir del «rey de España», dejando a los cristianos un inmenso botín.

En el número de enero de 1897, una revista mensual vienesa ${ }^{12}$ mencionaba además dos obras de teatro que contenían «la mentira mayor de la historia», pues tratan de la liberación de Viena por Carlos V y de que, nada menos, se batió en duelo con el Sultán:

Como el carácter de los españoles tiende a la fanfarronería - dice la revista- es comprensible que sus poetas se apoderen de un tema como éste, con predilección. Dos de sus mejores dramaturgos se atrevieron hasta a hacer subir al escenario, para que actuaran ante su público mostrando sus heroicidades guerreras, a varios grandes personajes, hasta hacerles salvar Viena de los paganos.

El primero de los dramas, que es a la vez el más antiguo e interesante, menciona al gran Lope de Vega como su autor. En el titular aparecen las palabras «Comedia Famosa» a doble tamaño que el resto. La revista Alt Wien dice que sólo existen tres

\footnotetext{
${ }^{12}$ Alt Wien, Momatsochrift für Wiener Art und Sprache.
} 


\section{VIENA POR CARLOS QVINTO. COMEDIA FAMOSA DE LOPE DE VEGA CARPIO.}

\section{Hablanen ella las perfonas.figuientes.}

Carlos Quinte. Don Hingo sirjo. Fuerse traguis. Ifidro fu beresano. inlians dims.
Inen Baturifa Capitall Antonio de Lejwe. Solinas Gran Turco. chriein reacgado. El Marques del Bafto.
El Rey don Eernande. Zelin Moro. Ejcander Btors. Maborad seres Yanos vitios. Vo foldado.

\section{ORNADA PRIMERA.}

Sale Fuerte Brequio Tob. s. Si de ral padre foy hijo, y hallo prefo a ral padre; entre otras obligaciones devo morir por librarle. Como no limo los hierrbs? como no rompo la carcel como no abrafo a Turquia? como no arrueno los ayres? No foy Aleman de origet, $y$ de una Alemana fangres ypor el Gran Carlos Quirito, no vengo arruynando alfanjes? Como no mato al gran. Turco, que con rerminos infanses una hermana me deshonra, y riene prefo a mi padre? A Soliman li zus obras ton $\mathrm{ml}$ deshonor fe faben, que hazes que no the remes, quien te anima $q$ me agraviest Eneralte en mi patria,y tierrz, en los fines A lemañes, y con quinientos mil Turcos agraviando miferables. Llegafte a mi cala antigua, herencia de mi linage, prendifte a ni padre en ella, dos hijos le cauri vafte. Supe la nueva en Viens, vine con reguro a hablarte, por mi padre;y mis hermanos, ofreciendote el refcate. $\mathbf{Y}$ con fer ley de la guerrz refcatar cautivos tales, niegafne nis caras prendas con intento de agraviarme. Pues yo hago juramento a la altera de mi fangrt, 2 las heridas de Chrilto, $y$ a las anfias de fo Madres a las vones del Bautifla, y a la Fe del Proromartit, a mis honradas promeffas, Y 2 mis penfamientos graves, de no bolver a Viena, ni de Turquia tornarme; de no falie de fu canipo, ni Je entrar en los Reales del Emnerador de ECpaña, hafta llevar a mi padre, aunque fe pere al gran Tureo, y todos fas Capitancs. sole If stro cos un coftily. Ifod. En lo gue en e! calaboço vifito al henrado prefo, y en lo que te verle goro. y en so que tus hierrosbeto; y fus defdichas follọ̧o. En lo que puedo esforgarle

Comedia Famosa de Lope de Vega Carpio: Viena por Carlos Quinto. Existen tres ejemplares de la primera edición, uno de ellos en la Biblioteca Nacional austriaca. 
ejemplares de esta obra: uno en la que hoy es la Biblioteca Nacional, el segundo en la biblioteca de Lord Holland en Kensington y el tercero en la Biblioteca Palatina de Parma.

El título «El cerco de Viena por Carlos Quinto» contiene de entrada un error de imprenta. Tendrá sentido si se hubiera impreso «El cerco de Viena y socorro por Carlos Quinto.» La revista añade que como las demás comedias españolas donde hay escenas de cristianos con paganos tiene un contenido religioso. En una escena, por ejemplo, Solimán envía a uno de sus generales llamado Ibrahim, que es un renegado, con un mensaje para Carlos V. En éste le dice que por haber una gran desproporción en el número de soldados y para evitar una gran matanza, sería mejor que en lugar de una batalla hubiera un duelo entre los dos. Carlos V se muestra conforme. Es curioso que no se mencione al duque de Alba y muy poco «al rey don Fernando». Seguidamente el Sultán se muestra decepcionado y con una gran depresión como reacción a la noticia del aniquilamiento de su avanzadilla de $\mathbf{1 6 . 0 0 0}$ jinetes, decidiendo no sólo desistir del duelo con Cartos V, sino, temiendo un gran fracaso, planear la retirada definitiva de sus tropas. Las últimas palabras de la «comedia famosa» son: «y ésta es la ilustre victoria que alcanzó España en Viena». El Emperador menciona el nombre de los que le acompañaban al alcanzar la ilustre victoria y allí sólo había españoles.

En la Jornada Primera, o sea, en el primer acto, sabemos de un tal Fuerte Braquio que nos explica:

Si de tal padre soy hijo, y hallo preso a tal padre, entre otras obligaciones devo morir por librarle. Cómo no limo los hierros? como no rompo la cácel? como no abraso a Turquía? como no atrueno los ayres? No soy Alemán de origen, y de una Alemana sangre? y por el Gran Carlos Quinto, no vengo arruynando alfanjes? Cómo no mato al gran Turco, que con términos infames una hermana me deshonra, y tiene preso a mi padre?

A Solimán, si tus obras con mi deshonor se saben, que hazes, que no me temes, quien te anima que me agravies? Entraste en mi patria y tierra, en los fines Alemanes, 


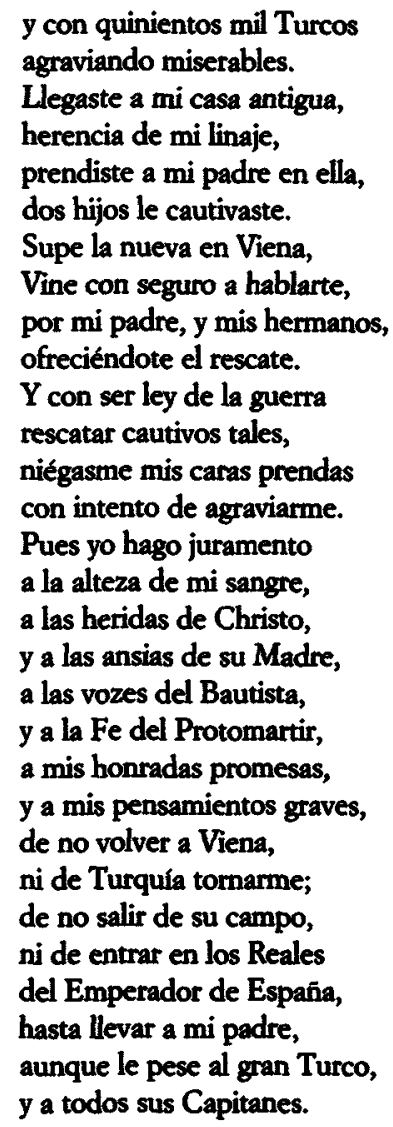

Comparando la fuerza dramática de esta obra con la de Francisco Rojas Zorrilla, que trata de la misma materia, podríamos decir que solamente psicológicamente es más interesante, pero también que es una de las más flojas de este escritor, entrado ya el siglo xvin. Tal como anuncia ya su título El desafio de Carlos V, Rojas Zorrilla mantiene la tradición de que hubo un desafio. Curiosamente el dramaturgo describe el estado lastimoso de salud en que está el Emperador. Ruega a Dios que le lleguen pronto tanto las provisiones como los sueldos. Su oración es escuchada, pues inmediatamente llega un emisario del papa Clemente VII con un escrito anunciando que 8.000 jinetes están en camino para reforzar las tropas imperiales y un millón de monedas. Estas noticias consuelan al Emperador y su ánimo mejora, pero seguidamente llega el turco Ibrahim con el escrito de Solimán en el que le desafía en un duelo, pues piensa que siendo cinco veces más fuerte en hombres y potencial bélico, el coraje y bravura personales decidirán quién se queda con todas las tierras danubianas. Carlos V, 
sorprendido por la propuesta, duda y no sabe si debe aceptar tan gran desafío. Sus generales le desaconsejan y también el duque de Alba. Sin embargo, el Emperador le pregunta a éste lo que haría si él fuera Carlos $\mathrm{V}$ y recibe como contestación que no dudaría aceptar el desafío. Ante esta respuesta el Emperador se pone su armadura y sale sin acompañamiento al lugar del duelo. Entretanto Solimán recibe la noticia de Ibrahim que Carlos $\mathrm{V}$ está en camino, deplora haberle hecho tal propuesta y sólo piensa en anularla. Sus consejeros y generales le dicen que no sería propio de él hacer esto y que mejor sería realizar inmediatamente el plan de ataque y sitio.

Los acontecimientos se van sucediendo. Los turcos sitian Güns que el dramaturgo confunde con Linz. Nicolitza (el conde Nicolaus Salm) es el defensor de Viena pero es el valiente Luis de Guevara, que dicen es hijo natural del duque de Albuquerque, quien ataca y dispersa a los turcos. Parece que sean los españoles los que salvaron Viena pero el orgullo hispánico no va tan lejos, pues deja constancia de la ayuda divina. Es gracias a san Martín, patrón de Linz (Günz), quien se aparece montando su caballo blanco y no partiendo su capa con su espada sino atacando a los turcos: estamos realmente frente a una variante del Santiago Matamoros.

Todos estos acontecimientos animan al Emperador, quien, a pesar de un fuerte ataque de gota, ha llegado al campo de batalla, una colina, donde ha de tener lugar el duelo con Solimán. Desde allí ve, sin embargo, que el Sultán se marcha seguido de una interminable fila de soldados, pues han preferido salvar la vida y luchar otro día en otro lugar...

Esta obra de teatro termina con la boda de don Luis de la Cueva con Leonor, la hija de Nicolitza (el defensor de Viena). La mencionada revista mensual comenta que con este final tampoco se puede negar que es típicamente española, pero manifiesta su sorpresa por el realismo del drama, al describir (un siglo después) las enfermedades y subrayar la frágil salud del Emperador, junto con su miseria financiera y las dudas ante la solución de los diferentes peligros de la guerra.

El contenido de ambas obras teatrales y, de una forma mas drástica, de los dos romances, es la exaltación de la figura del Emperador. La confusión de los hechos y de las fechas parece ser cien por cien voluntaria: era sólo cuestión de lograr el objetivo apoteósico. Repito que quien busque en ellas la descripción de los sucesos en forma de crónica buscará en vano, pero verá reflejada literariamente un suceso de enorme importancia en el que célebres poetas hispánicos, como Lope, Rojas o Garcilaso, centraron su quehacer lírico-dramático.

En el Museo de la Ciudad de Viena hay algunos objetos expuestos que testimonian tanto lo sucedido en 1529 como en 1532 . Se puede admirar una bandera perteneciente a las tropas españolas que defendieron la ciudad. Mide $217 \times 405 \mathrm{~cm}$, es cuadrangular y pintada por ambos lados sobre seda roja. Allí están los escudos de la Casa de Austria, de la Vieja y Nueva Borgoña, de Brabante, Tirol, Castilla, León, Aragón y Sicilia. En una punta se puede observar una Granada y en la otra el año 1523. Hasta el siglo XVI existió otra bandera igual de los Tercios, con la fecha del año 1529. 


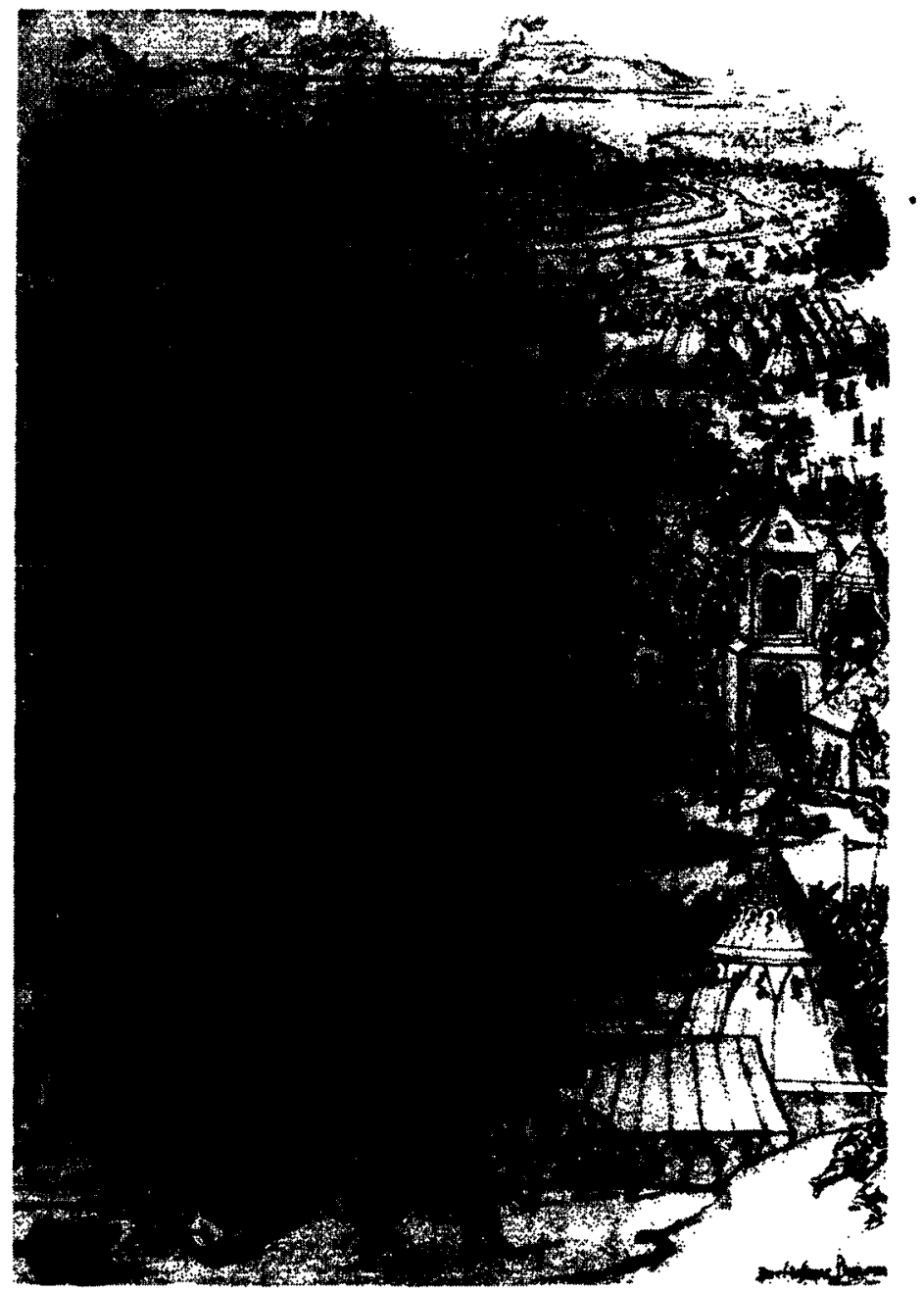

Grabado de Bartolomé Behom titulado «Vienna defessa a Solimanno, anno Domini, 1529». Muestra el campamento otomano al sur de la capital, pudiéndose reconocer en el centro la aguja gótica recientemente restaurada «Spinnerin am Kreuzw. Museo Municipal de Viena.

En una serie de cinco cuadros, Michael Ostendorfer (1490-1559) pintó un exacto bosquejo de lo que habria de trabajarse en relieve sobre madera: una representación de las tropas imperiales estacionadas a la altura de Viena, en la orilla izquierda del Danubio. Se dijo que este contingente calculado en 100.000 hombres kera el más bello ejército de la cristiandad». Los dibujos de Ostendorfer tienen actualmente gran impor- 


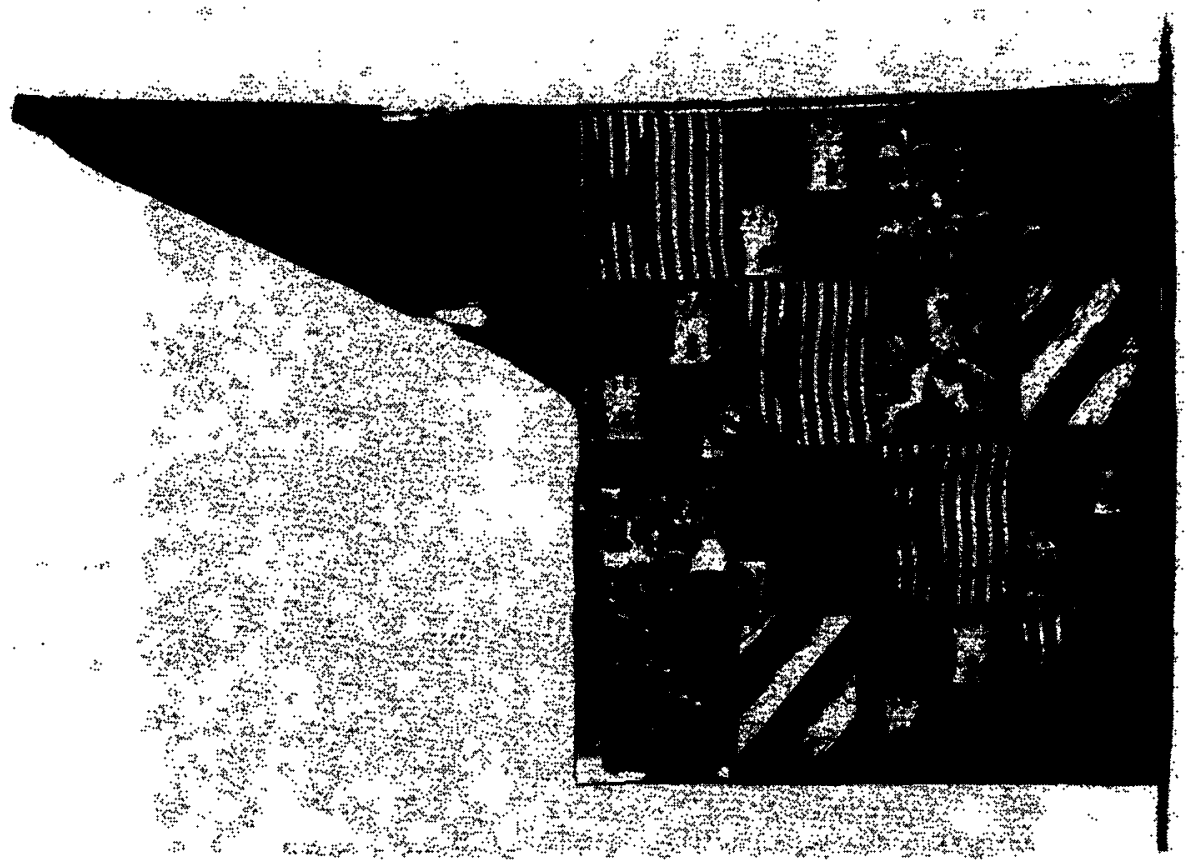

Bandera de los Tercios españoles de Flandes que defendieron Viena en el primer cerco: se calcula fueron unos 750 hombres de los que sólo menos de la mitad sobrevivió. Vemos los escudos de la Vieja

y Nueva Borgona, Bravante, Tirol, Castilla-León con Granada, Cataluña-Aragón, asi como Sicilia. Museo Municipal de Viena.

tancia, pues con ellos se puede tener idea de cómo eran en la Baja Austria las ciudades, mercados, castillos, etc.

En el catálogo del mencionado «Museum der Stadt Wien» se dice que:

En verano de 1532 Solimán pretendió de nuevo llegar hasta Viena escogiendo una ruta situada más al sur, pero que la pequeña fortaleza de Günz, defendida con gran coraje por Nikolaus Jurischitsch, prestó una larga y valiente resistencia. Finalmente, ante un diluvio incesante, los turcos regresaron tomaron la ruta del sur y pasando por la Estiria. Los jinetes tártaros, esparcidos por los bosques de Viena, fueron perseguidos y aniquilados. La presencia de un fuerte ejército reunido bajo el emperador Carlos $V$ en los alrededores de Viena fue determinante para que los turcos se retiraran.

Por último puedo mencionar que en el citado Museo hay una gran Media Luna y una gran Estrella de ocho puntas, de cobre, que representaban el poder civil y eclesiástico, es decir, que eran un símbolo del Emperador y del Papa. Nadie recordó dicha simbologia, pero en Viena se esparció la leyenda que llega hasta nuestros días de que Solimán sólo se marchó de Viena cuando le aseguraron que pondrían en la punta de 


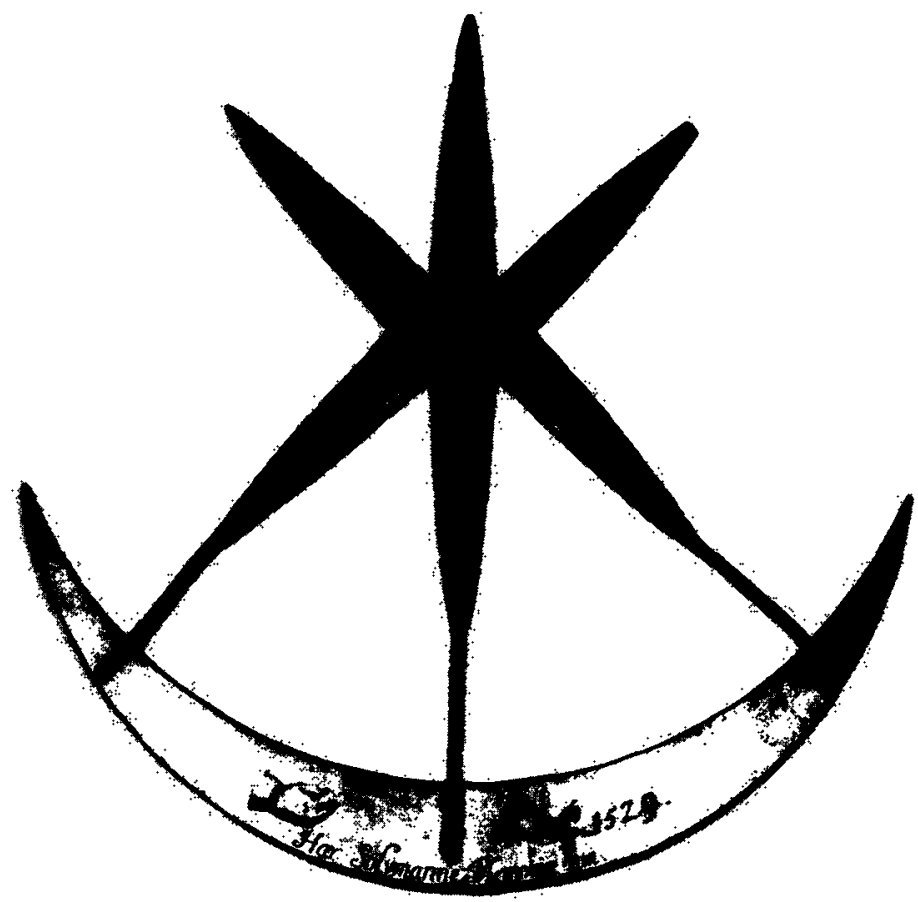

Media luna y estrella de seis puntas que coronaban la punta de la única torre de la Catedral de San Esteban. El entonces archiduque Fernando hizo gravar la fecha del año 1529 y la inscripción latina $\ll$ Haec Solymanne Memoria tua», con una mano en la que el dedo pulgar se coloca entre el índice y el dedo medio. Era un gesto muy poco fino y de desprecio, que algunos llamaban thacer la higax. Museo Municipal de Viena.

la «Steffl», que así llaman a la torre de la catedral, tanto la media luna como la estrella. Despues del segundo cerco de Viena, en 1683, el emperador Leopoldo I hizo desmontar y apartar estos «símbolos paganos», poniendo en su lugar y por amor a su primera esposa Margarita Teresa, hija de Felipe IV, una «cruz española» que no era otra que una cruz llamada patriarcal o también de Lorena, de doble asta transversal. Desde entonces sigue en su lugar a pesar de la destrucción de gran parte de la catedral de san Esteban a fines de la Segunda Guerra Mundial. 